

\section{ÉPOCAS RECOMENDADAS PARA LA SIEMBRA DEL CAFE EN COLOMBIA}

Álvaro Jaramillo Robledo *

Siembre oportunamente para no perder ciclos productivos.

En los cafetales recién sembrados es frecuente observar el retraso en el crecimiento o hasta la muerte de las plantas en el campo, debido a la falta de agua en los meses posteriores a la siembra. Esta situación se vuelve más crítica durante los eventos de El Niño, por disminución de la cantidad de lluvia y por la mayor duración de los períodos secos. Cuando se siembra en el período recomendado se evitan las pérdidas para el caficultor.

\section{Periodos secos y húmedos en la zona cafetera}

La cantidad de lluvia y su distribución determinan la magnitud y la duración de los períodos secos y húmedos de una región, y estos a su vez condicionan la dinámica del crecimiento vegetativo y reproductivo del café, las épocas del año con mayor o menor crecimiento, la concentración de las floraciones, el desarrollo del fruto y la cosecha.

La distribución regional de la lluvia es la base para la toma de decisiones en la caficultura, por ejemplo, cuál es el momento oportuno para sembrar el cafetal con el menor riesgo de pérdida, la planificación y el tipo de prácticas agronómicas a desarrollar, la utilización o no de sistemas agroforestales transitorios o permanentes, las épocas de fertilización, el manejo de arvenses y los controles fitosanitarios, entre otros. 
Los patrones de distribución anual de la lluvia en las regiones cafeteras de Colombia dependen de la confluencia de los vientos Alisios del Noreste, procedentes del océano Atlántico, y de los Alisios del Sureste, que ingresan desde la Amazonía y por el océano Pacífico.

En los extremos geográficos de Colombia, por ejemplo, para la Sierra Nevada de Santa Marta en el Norte, y para los departamentos de Nariño y Cauca en el Sur, se presenta un período seco y un período húmedo durante el año; para latitudes mayores de $7^{\circ}$ Norte (Zona Cafetera Norte) el período seco ocurre de diciembre a abril y el húmedo de mayo a noviembre. Para latitudes inferiores a los $3^{\circ}$ Norte (Zona Cafetera Sur) el período seco se presenta desde junio a septiembre y el período húmedo de octubre a mayo.

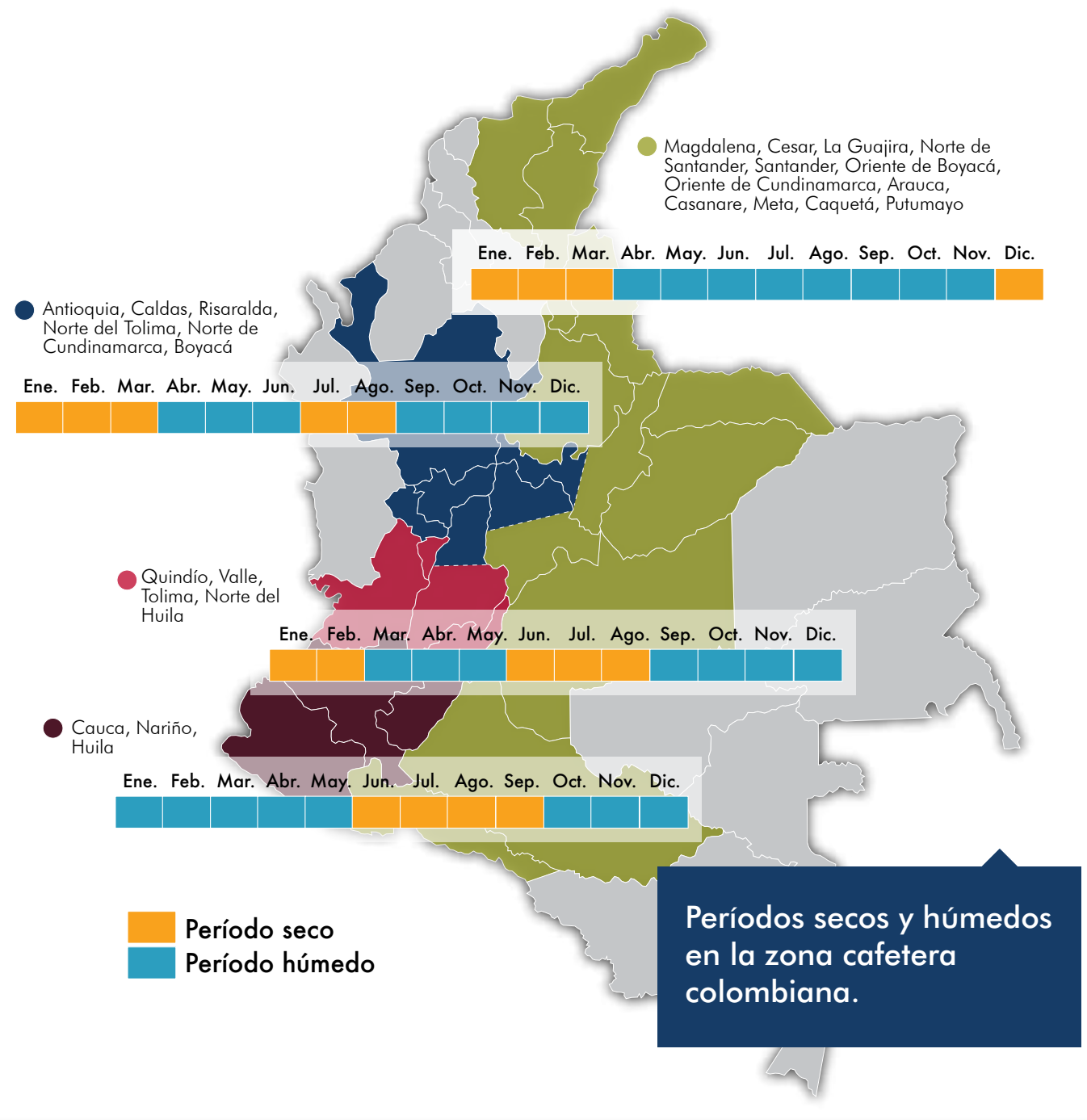


En general, para latitudes entre los $3^{\circ}$ y $7^{\circ}$ Norte (Zona Cafetera Central) se presentan dos períodos lluviosos: abril-mayo y octubre-noviembre y dos períodos menos lluviosos febrero-marzo y julio-agosto.

\section{Meses recomendados para la siembra del café}

Para recomendar las épocas más favorables para la siembra del café es necesario conocer con un alto nivel de seguridad la ocurrencia de los meses secos, húmedos y muy húmedos de las diferentes zonas cafeteras.

Los meses recomendados para la siembra del café son al inicio del período de lluvias de la región, lo cual garantiza que el suelo tenga las condiciones de humedad adecuadas para el crecimiento de cafeto y con suficiente duración para asegurar el establecimiento de las plantas en el campo.

Meses recomendados para el inicio del establecimiento del germinador, el almácigo y la siembra del café en Colombia.

\begin{tabular}{|l|l|l|l}
\multicolumn{1}{|c|}{ Departamento } & \multicolumn{1}{|c|}{$\begin{array}{c}\text { Germinador } \\
\text { (Dos meses } \\
\text { antes del almácigo) }\end{array}$} & $\begin{array}{c}\text { Almácigo } \\
\text { (Seis meses antes } \\
\text { de la siembra) }\end{array}$ & \multicolumn{1}{|c}{$\begin{array}{c}\text { Siembra en el } \\
\text { campo }\end{array}$} \\
\hline Antioquia & Agosto o enero & Octubre o marzo & Abril o septiembre \\
\hline Boyacá & Agosto & Octubre & Abril \\
\hline Caldas & Agosto o enero & Octubre o marzo & $\begin{array}{l}\text { Marzo o } \\
\text { septiembre }\end{array}$ \\
\hline Cauca & Febrero & Abril & Octubre \\
\hline Cesar & Agosto & Octubre & Abril \\
\hline Cundinamarca & Agosto o febrero & Octubre o abril & Marzo u octubre \\
\hline La Guajira & Septiembre & Noviembre & Mayo \\
\hline Huila & Febrero o agosto & Abril & Octubre \\
\hline Magdalena & Agosto & Abril u octubre & Abril \\
\hline Nariño & Febrero & Abril & Octubre \\
\hline $\begin{array}{l}\text { Norte de } \\
\text { Santander }\end{array}$ & Agosto & Octubre & Abril \\
\hline Quindío & Julio o febrero & Septiembre o abril & Marzo u octubre \\
\hline
\end{tabular}

Continúa... 


\begin{tabular}{|l|l|l|l|}
\multicolumn{1}{|c|}{ Departamento } & \multicolumn{1}{|c|}{$\begin{array}{c}\text { Germinador } \\
\text { (Dos meses } \\
\text { antes del almácigo) }\end{array}$} & $\begin{array}{c}\text { Almácigo } \\
\text { (Seis meses antes } \\
\text { de la siembra) }\end{array}$ & $\begin{array}{c}\text { Siembra en el } \\
\text { campo }\end{array}$ \\
\hline Risaralda & Julio o febrero & Septiembre o abril & Marzo u octubre \\
\hline Santander & Agosto & Octubre & Abril \\
\hline Tolima & Julio o febrero & Septiembre o abril & Marzo u octubre \\
\hline Valle del Cauca & Julio o febrero & Septiembre o abril & Marzo u octubre \\
\hline $\begin{array}{l}\text { Arauca - Casanare } \\
\text { - Meta - Caquetá - } \\
\text { Putumayo }\end{array}$ & Agosto & Octubre & Abril \\
\hline
\end{tabular}

Es de anotar que, en regiones muy secas, con períodos secos prolongados, como en Norte de Santander y Santander, la tendencia general es la ocurrencia de un período húmedo desde abril a noviembre y se recomendaría la siembra del café a finales de abril.

En la región cafetera Norte el período húmedo se inicia a finales de marzo y en la zona cafetera Sur a finales de septiembre, por tal razón, aunque estos meses se vean como húmedos, la recomendación para la siembra sería en abril o en octubre, respectivamente.

\begin{tabular}{l} 
La semilla para los almácigos de café debe estar en los germinadores \\
entre 6 y 8 meses antes del trasplante definitivo en el campo; de este \\
período, dos meses corresponden a la etapa del germinador, y 4 a \\
6 meses a la etapa de almácigo, dependiendo del tamaño de bolsa \\
utilizada. En zonas cafeteras con temperatura media inferior a $19^{\circ} \mathrm{C}$, \\
\hline la semilla debe estar en el germinador 8 a 10 meses antes.
\end{tabular}

\section{Ajustes en las épocas de siembra en condicion de El Niño}

Cuando se presenta un evento de El Niño en la zona cafetera, disminuye la cantidad de lluvia en el período húmedo y se acentúa la magnitud y la duración del período seco, con aumentos de la temperatura y la radiación solar. Por lo general, estas condiciones se presentan durante el período activo de El Niño, que normalmente tiene una duración de un año, desde el inicio en mayo-junio hasta junio a julio del año siguiente. 
Durante la mayor actividad de El Niño, especialmente para eventos de carácter moderado a fuerte, resulta de alto riesgo la siembra del café por muerte de las plantas en el campo.

En regiones secas, con baja precipitación (menos de $1.500 \mathrm{~mm}$ al año) o durante los eventos de El Niño, se recomienda utilizar sombrío transitorio en los lotes donde se va a establecer el café, sembrando leguminosas, como por ejemplo, tefrosia, guandul o crotalaria.

Para conservar la humedad y mejorar las propiedades físicas del suelo es recomendable el uso de coberturas en el plato del árbol.

Durante el evento de El Niño, especialmente en regiones de baja precipitación y durante los meses normalmente secos, no se recomienda la siembra de cultivos como fríjol o maíz.

En esta época pueden adelantarse las labores de zoqueo y aprovechar el material de ramas cortadas para cubrir el plato del árbol.

\section{Ajustes en las épocas de siembra en condición de La Niña}

Cuando se presenta un evento de La Niña, especialmente en la Zona Cafetera Central (entre los $3^{\circ}$ y $7^{\circ}$ Norte), aumenta la cantidad de lluvia, los períodos secos son más cortos o no se presentan y disminuyen la temperatura y la radiación solar. Por lo general, estas condiciones ocurren de manera continua durante un año o más, las cuales garantizan la disponibilidad de agua $y$, por tal motivo, puede sembrarse el café en las épocas recomendadas.

Tanto para las condiciones de El Niño como para La Niña debe
hacerse un seguimiento continuo en la plataforma agroclimática
de Cenicafé https://agroclima.cenicafe.org para evaluar su
comportamiento y así tener los elementos para tomar decisiones
seguras en las prácticas agronómicas.




\section{Ijpocas para la siembra dề eató}

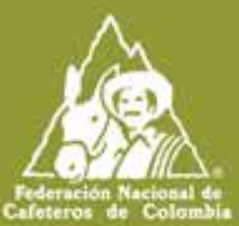

La distribución regional de la lluvia es la base para la toma de decisiones en la finca, como:

Momento oportuno para sembrar el cafetal con el menor riesgo de pérdida.

\section{Prácticas agronómicas en las etapas de} germinador, almácigo y en el establecimiento de las plantas en el campo.

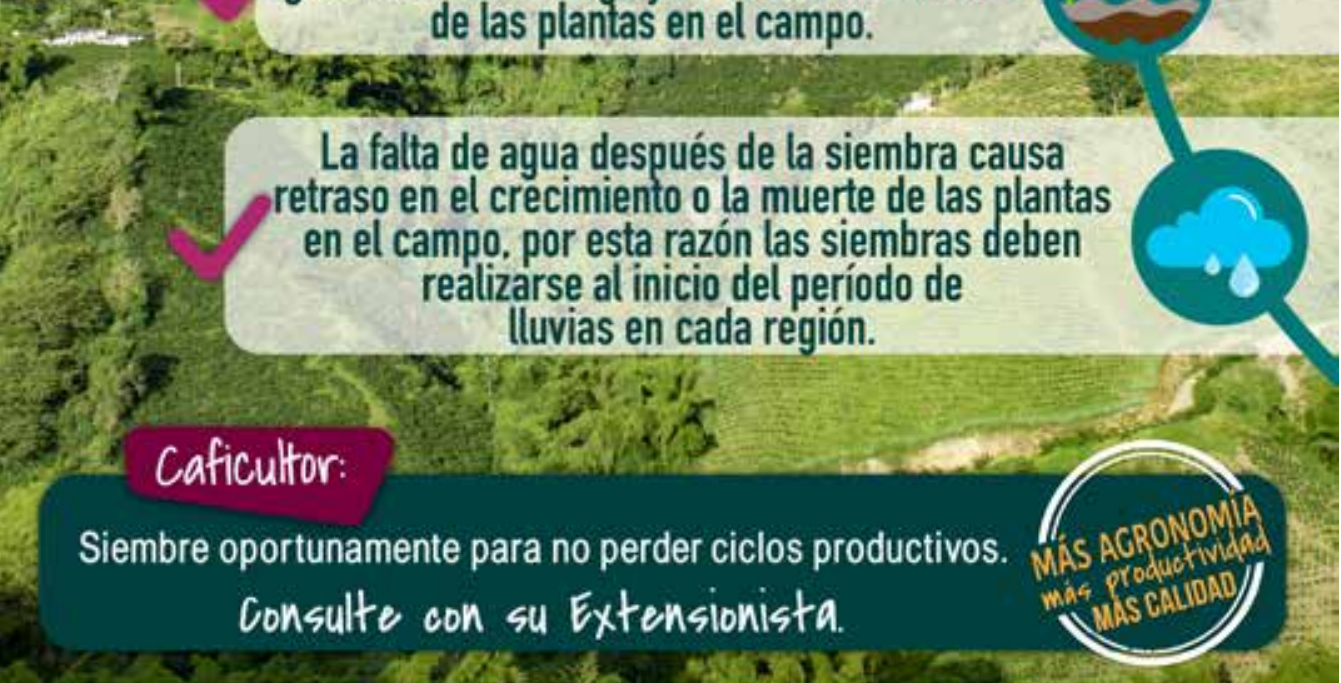




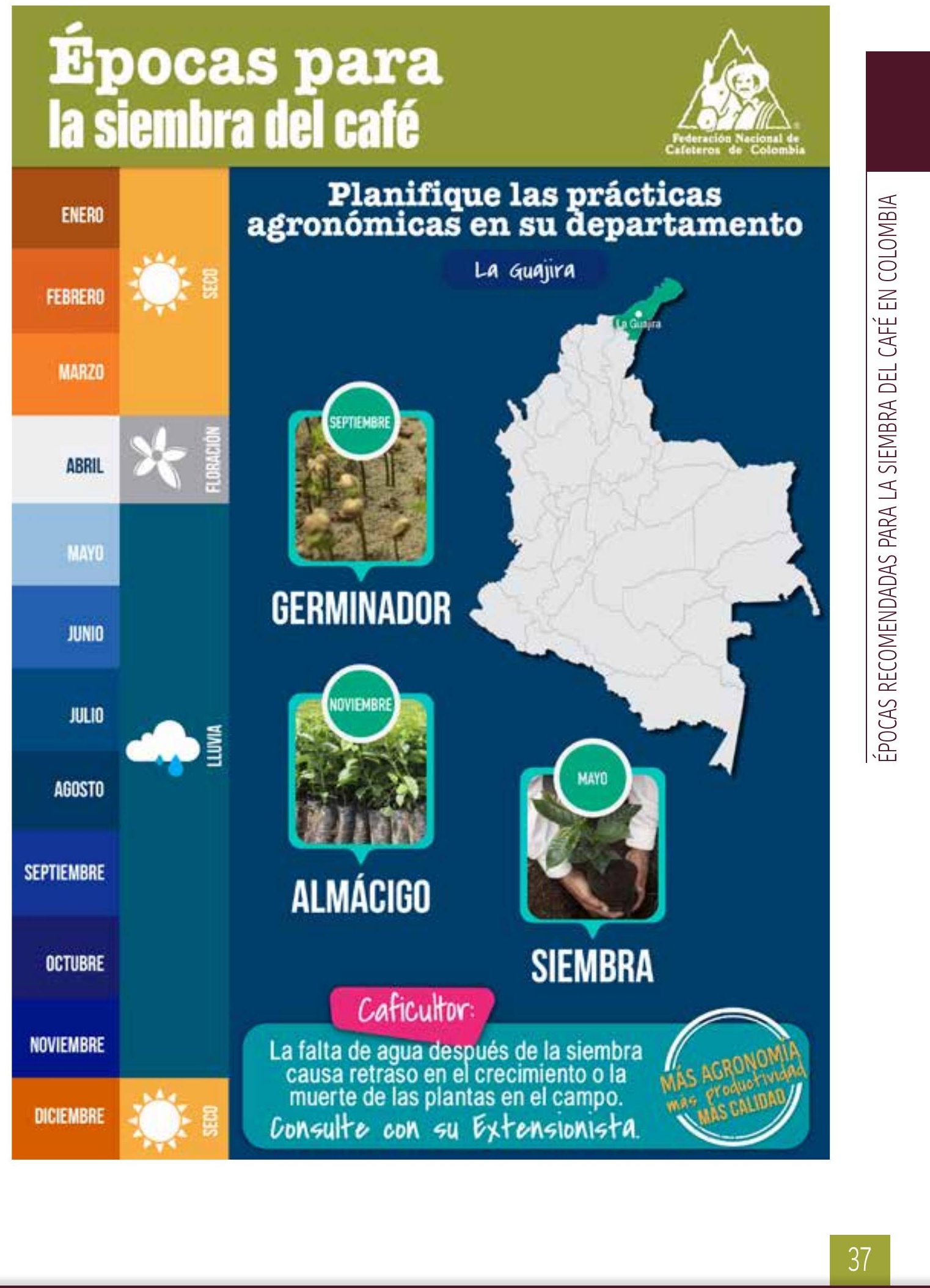




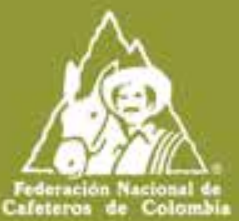

ENERO agronómicas en su departamento
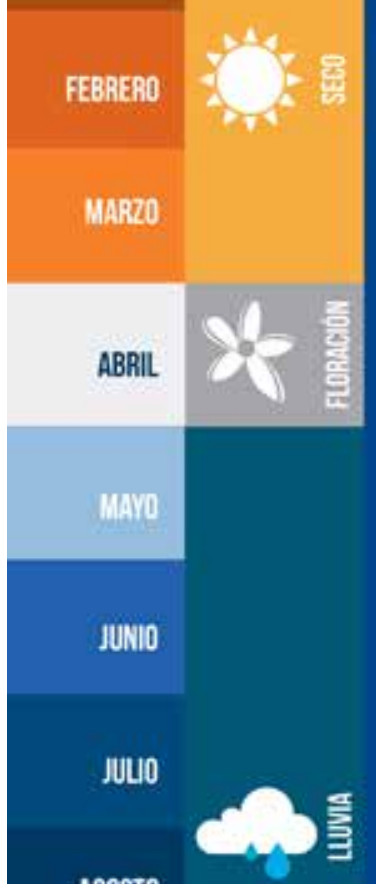

Magdalena, cesar, santander, Norte de santander, Boyacá, Arauca, casanare, Meta, caquetá,

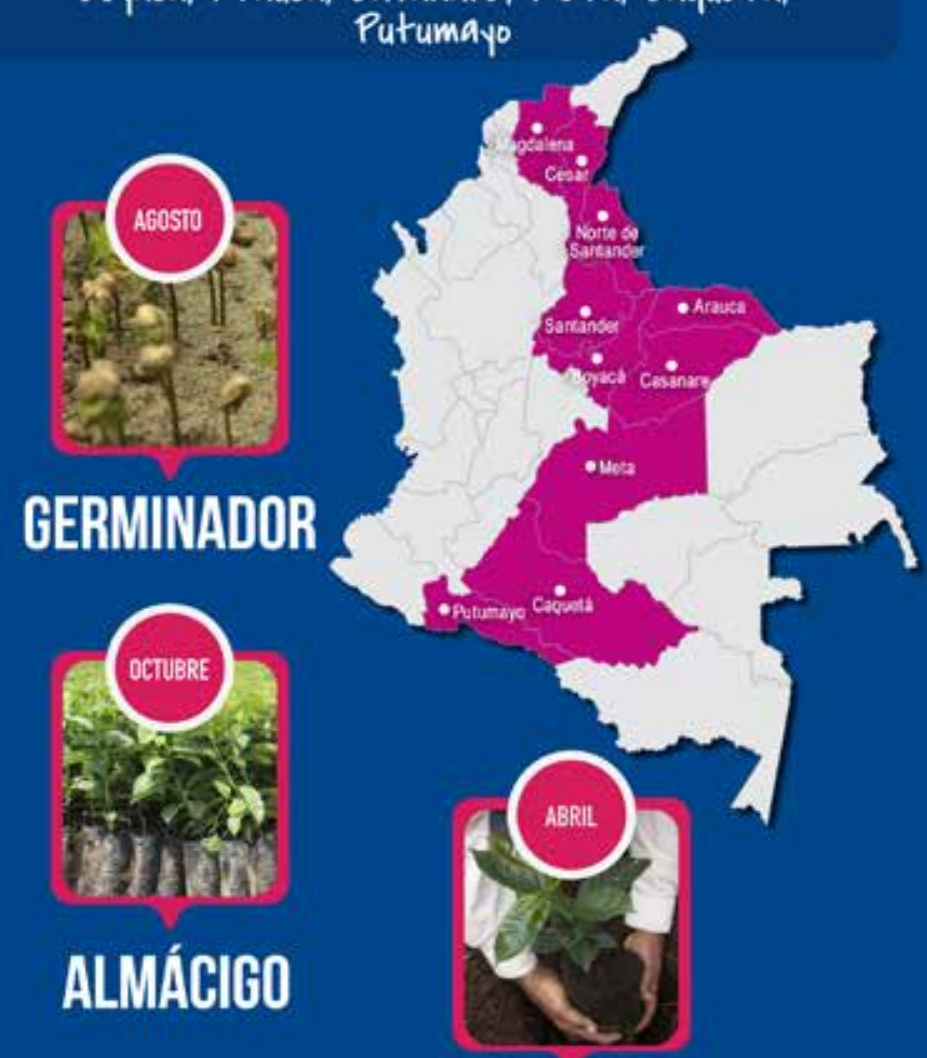

OCTUBRE

SEPTIEMBRE

\section{ALMÁCIEO}

\section{SIEMBRA}

NOVIEMBRE

Recuerde que las siembras deben realizarse al inicio del periodo de lluvias DCIEMBRE en cada región. consulte con su Extensionista. 


\section{Ijpocas para la siembra dêl eafté}

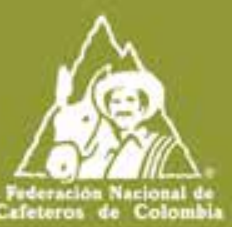

\section{Planifique las prácticas agronómicas en su departamento}

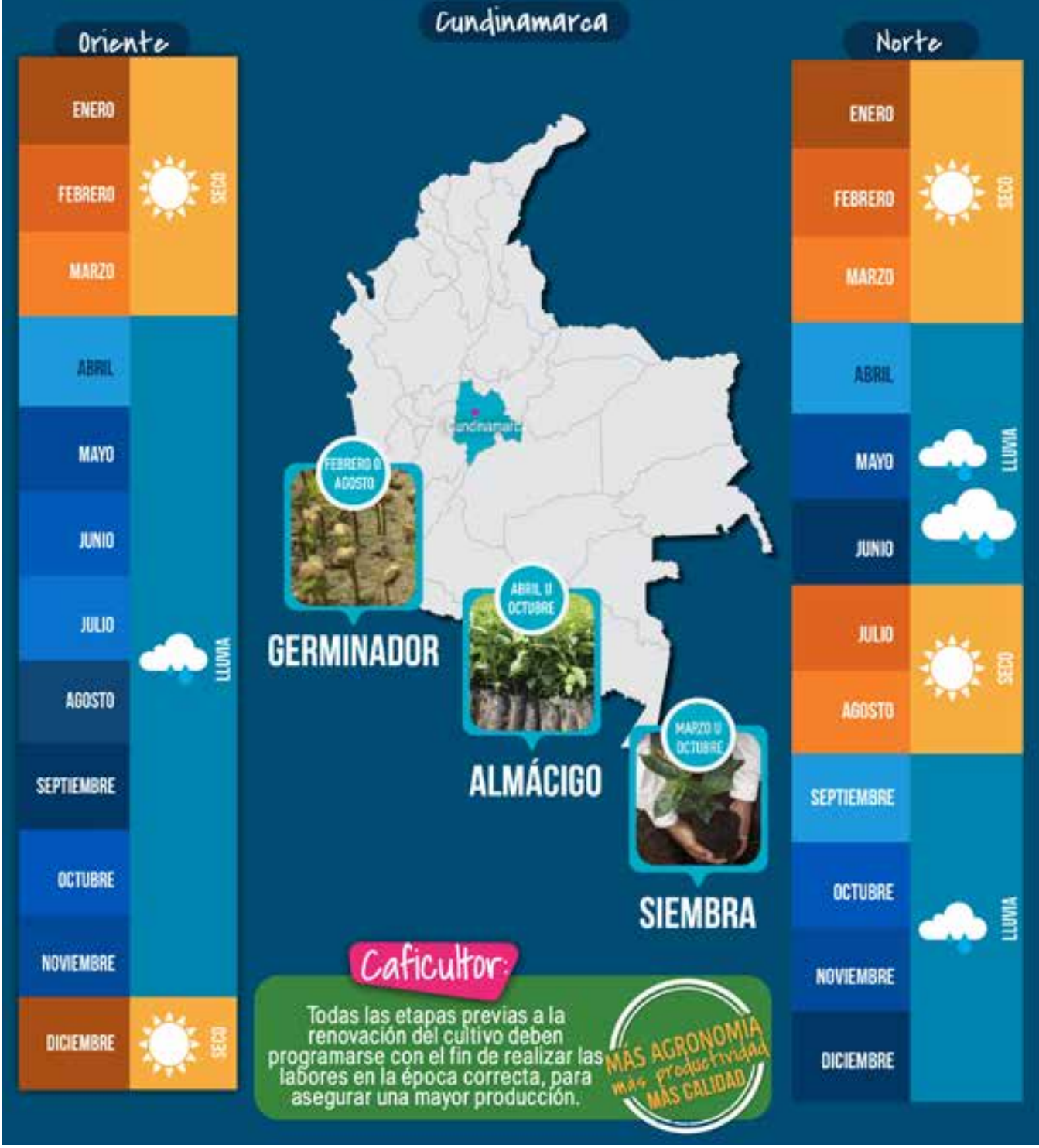




\section{Ijpocas para la siembra dêt eatét}

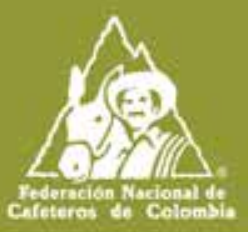

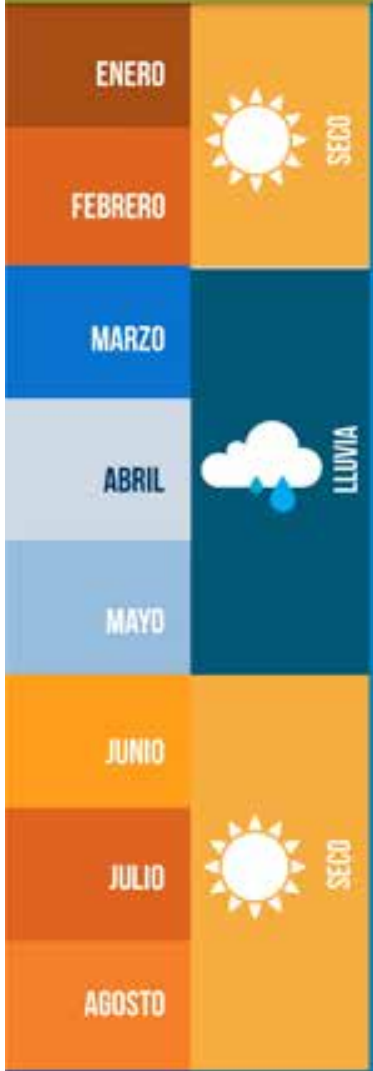

SEPTIEMBRE

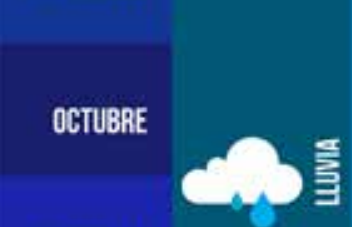

NOVEMBRE

DICIEMBRE

\section{Planifique las prácticas agronómicas en su departamento}

Risaralda - Quindio - Tolima - Valle del cauca

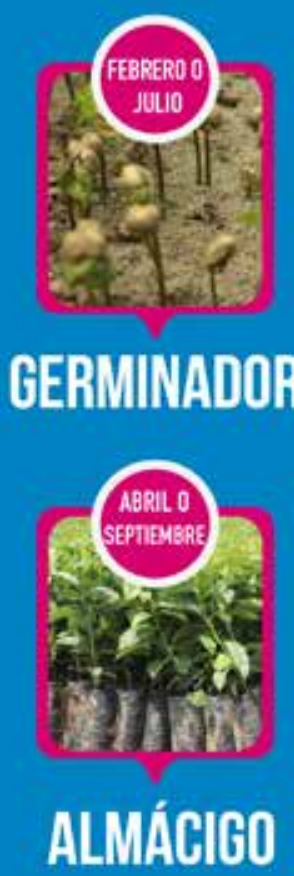

Caficultor:

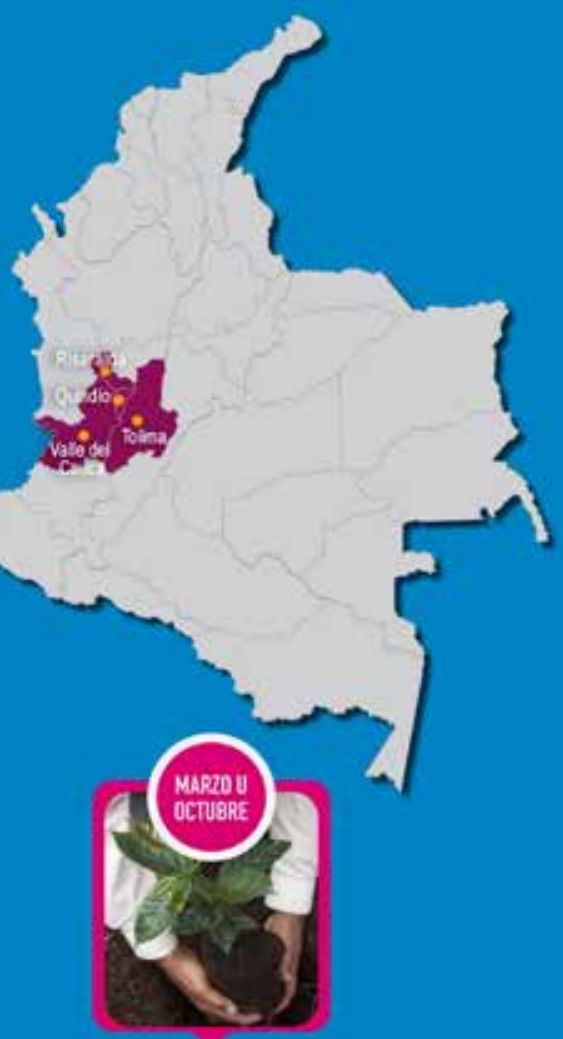

\section{SIEMBRA}

El establecimiento del cultivo en las épocas recomendadas disminuye la pérdida de sitios y asegura una mejor producción. Consulte con su Extensionista.

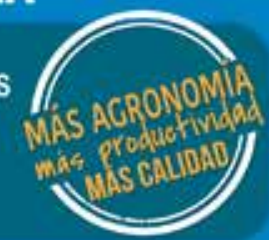




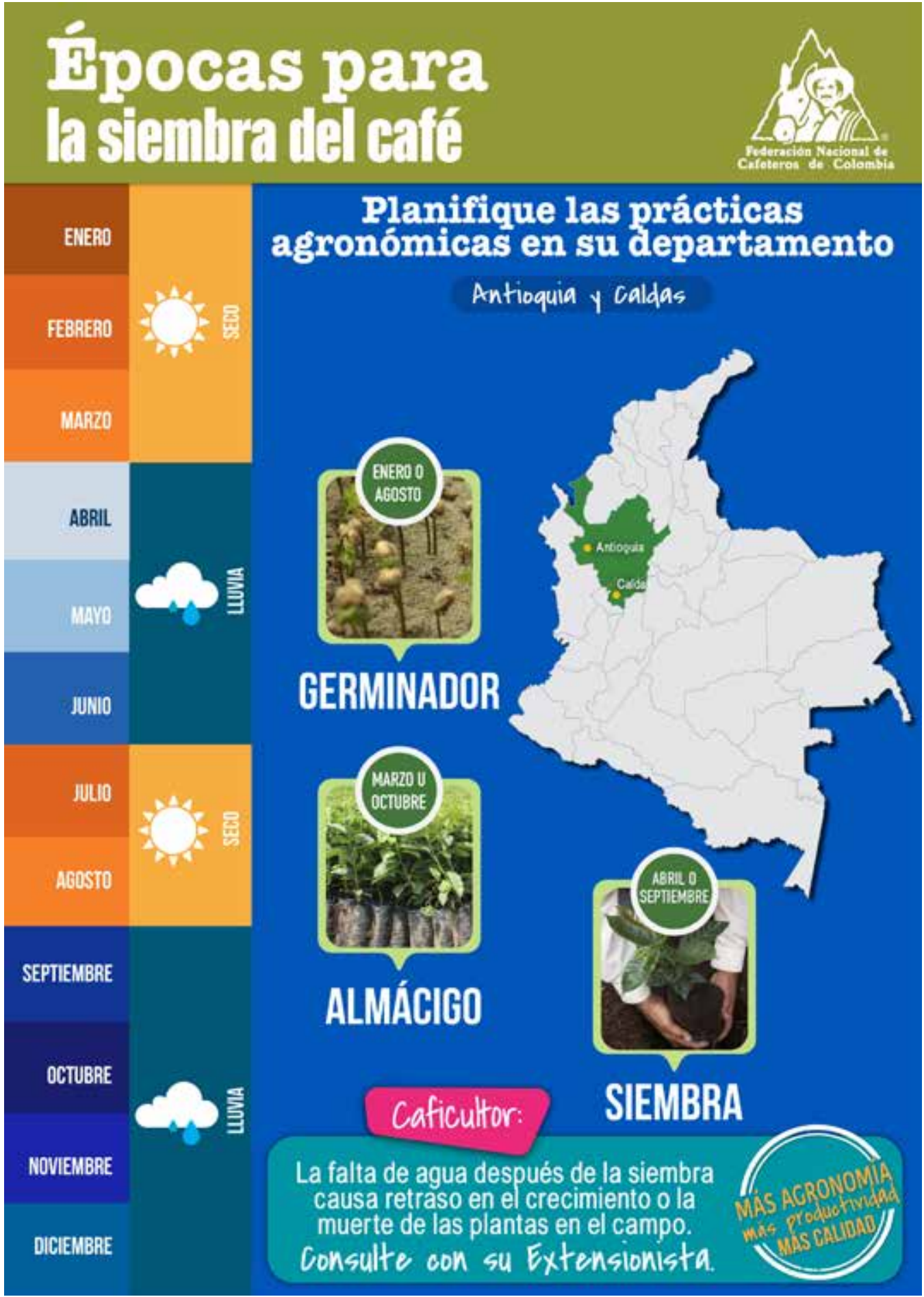




\section{İpocas para la siembra idel eaftó}

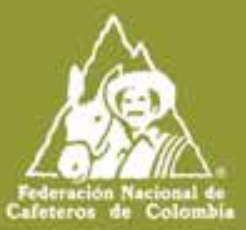

Planifique las prácticas agronómicas en su departamento

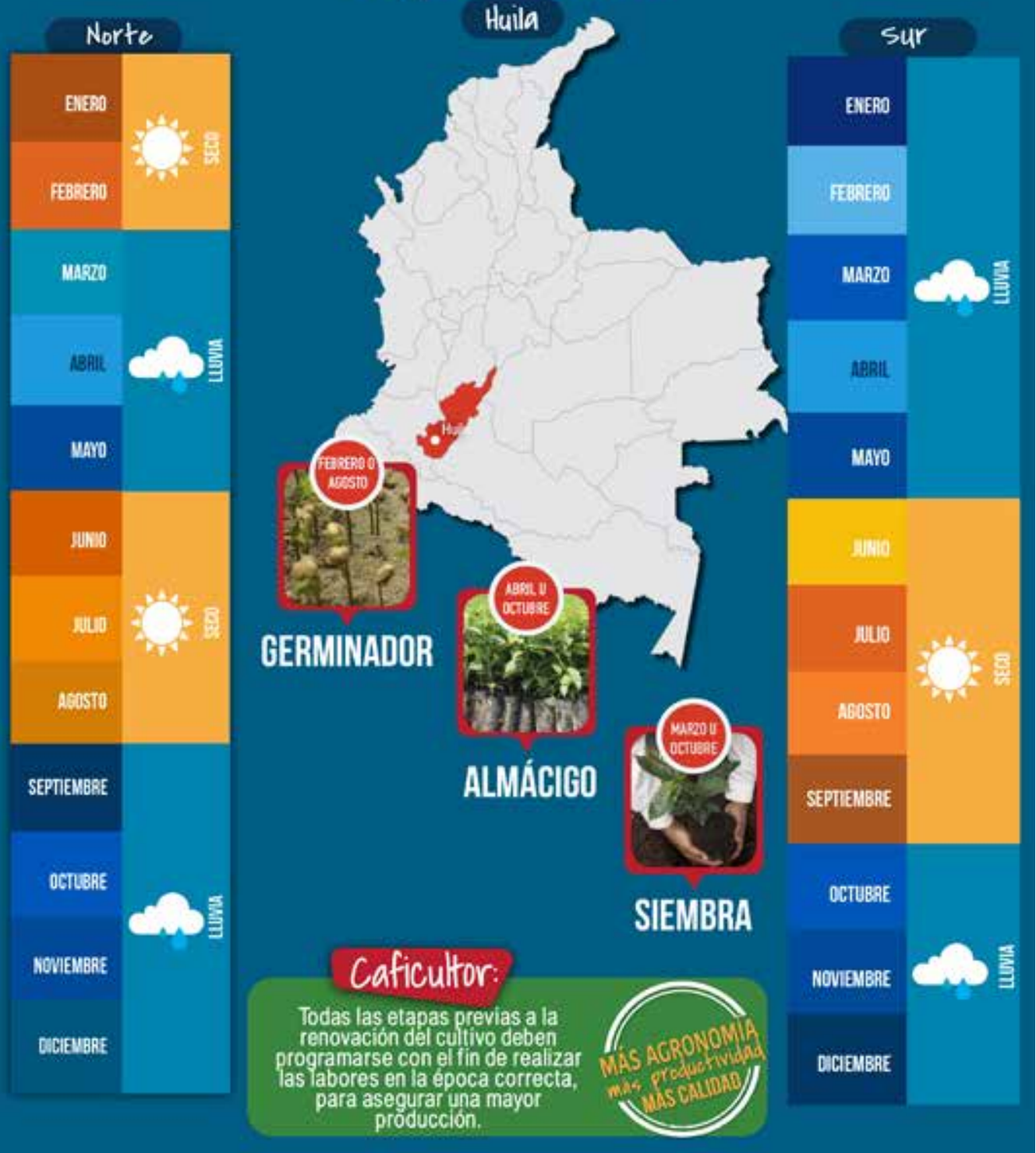




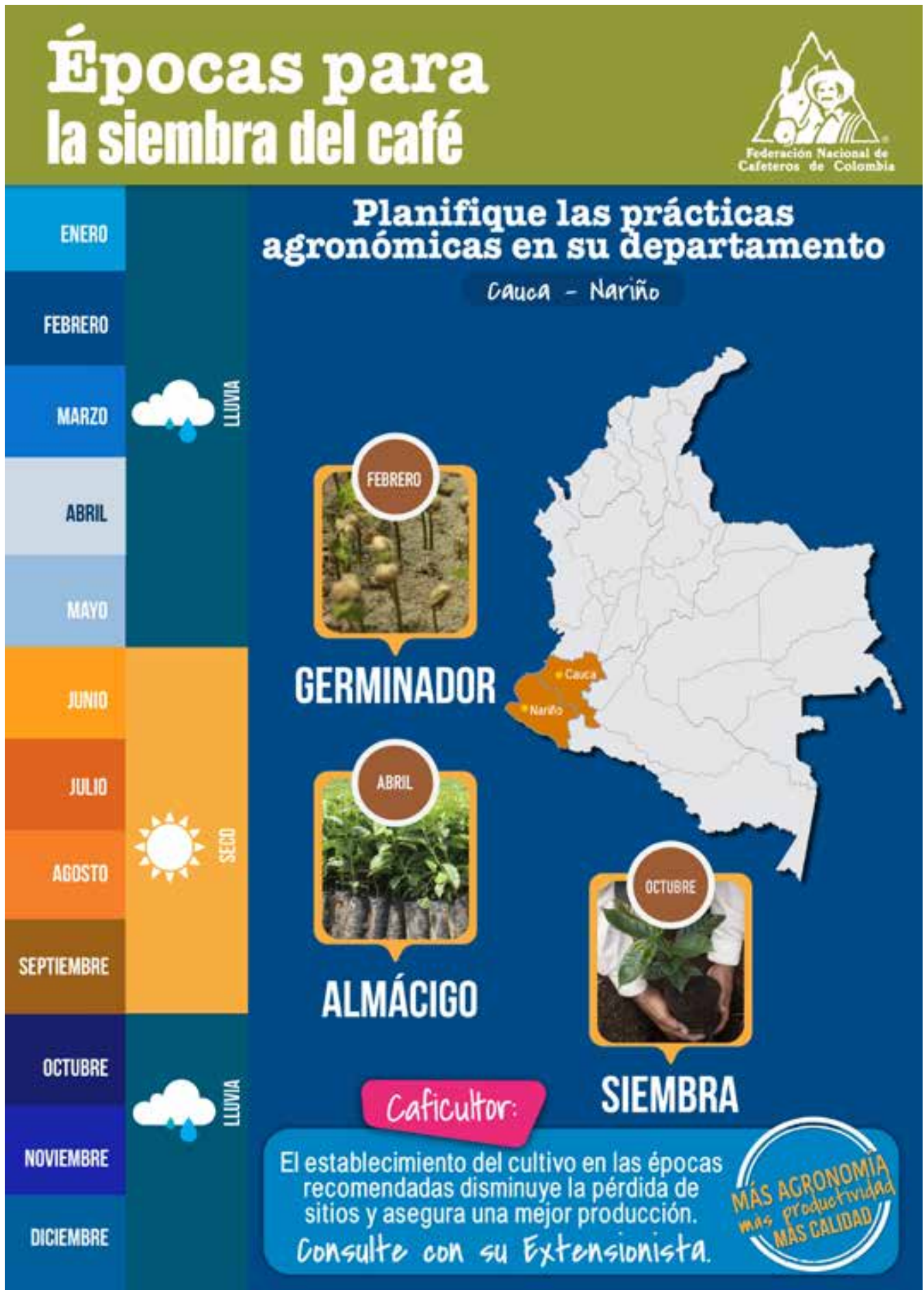

